\title{
Caracterização das Casas de Apoio a portadores de HIV/Aids em Ribeirão Preto (São Paulo, Brasil) e suas práticas de administração
}

\author{
Marisley Vilas Bôas Soares ${ }^{1}$ \\ Aldaísa Cassanho Forster ${ }^{2}$ \\ Manoel Antonio dos Santos 3
}

SOARES, M.V.B.; FORSTER, A.C.; SANTOS, M.A. Characterization of support houses for people with HIV/Aids in Ribeirão Preto (São Paulo, Brazil) and their administrative practices. Interface - Comunic., Saúde, Educ., v.12, n.24, p.169-80, jan./mar. 2008.

The study aimed to determine how three support houses for people with HIV/Aids in Ribeirão Preto, SP, are organized and operated by their coordinators, and how care is provided. Semi-structured interviews were held regarding coordination functions. Structural characteristics of the locality were probed and daily institutional life was recorded using a field diary. It was found that, legally, these organizations are governed by assistance-providing and humanitarian entities that sought to conform to operational technical standards and requirements. They received subsidies from local municipal authorities but were especially maintained through donations from civil society. Women predominated among the employees and volunteers and were the coordinators. From their words, they had a multifunctional administrative stance and had difficulty in achieving social inclusion for the residents because of prejudice or the rules for how the houses should function. In conclusion, the houses are what they purport to be administratively, but should be attentive towards the need, as social agents, to encourage social inclusion.

Key words: Recuperation houses. HIV. Acquired immunodeficiency syndrome. Care. Social inclusion
Objetivou-se conhecer a organização, o funcionamento e a prestação da assistência de três Casas de Apoio a portadores de HIV/ Aids em Ribeirão Preto-SP. Foram feitas entrevistas semi-estruturadas com as coordenadoras a respeito de suas funções, aplicou-se um questionário sobre os aspectos estruturais do local e registraram-se observações do cotidiano das instituições. Legalmente, eram organizações regidas por entidades de cunho assistencialistahumanitário e procuravam adequar-se às normas técnicas e exigências para seu funcionamento. Recebiam subvenção da prefeitura local, mas eram sustentadas, sobretudo, por doações da sociedade civil. As coordenações eram desempenhadas por mulheres, predominantes nos quadros de funcionários e voluntários. Em suas falas, observou-se uma postura administrativa multifuncional e dificuldade para realizar a inclusão social dos moradores, devido a preconceito ou regras de funcionamento das casas. Conclui-se que, administrativamente as Casas correspondiam ao que se propunham, mas deveriam atentar para a necessidade, como agentes sociais, de fomentar a inclusão social.

Palavras-chave: Casas de recuperação. HIV. Síndrome da imunodeficiência adquirida. Cuidado. Inclusão social. 


\section{Introdução}

Os serviços de cuidado às pessoas portadoras do vírus HIV são oferecidos, atualmente, junto à rede assistencial do Sistema Único de Saúde (SUS), por meio de programas governamentais (Programa Nacional de Combate à Aids, Centros de Testagem e Aconselhamento - CTA, entre outros) e iniciativas organizadas e mantidas pela sociedade civil, como Organizações Não Governamentais (ONG) e as denominadas Casas de Apoio.

Observa-se que o termo Casa de Apoio possui uma utilização diversa, pois pode abranger públicos e objetivos diferenciados. Têm-se, por exemplo, instituições-abrigo para mulheres vítimas de violência (Meneghel et al., 2000), bem como para pessoas em tratamento de saúde e seus acompanhantes - vide experiências, como associações de combate ao câncer, existentes em várias cidades do país, como os GACC (Grupo de Apoio à Criança com Câncer), Casa Hope, entre outras. Todas são, no entanto, voltadas a oferecer um recurso de assistência e cuidado a uma clientela que, particularmente, esteja vivenciando uma situação de maior vulnerabilidade emocional e/ou física.

Data de 1985 o surgimento da primeira Casa de Apoio para portadores do HIV, a Casa de Apoio Brenda Lee, a primeira do gênero na América do Sul (Ramos, 2004; Galvão, 2002). Abadia-Barrero (2002) refere que, na década de 1990, houve uma expansão das casas de apoio e outros trabalhos assistenciais às pessoas soropositivas.

As Casas de Apoio a portadores de HIV/Aids são organizações da sociedade civil, de caráter privado, com interesse público e sem fins lucrativos, majoritariamente mantidas com recursos que provêm da sociedade. Configuram-se como equipamentos para acolhimento e acesso à assistência multidisciplinar à saúde de portadores sem recursos financeiros e/ou condições familiares para a convivência diária com as demandas que a síndrome acarreta no seu cotidiano (Brasil, 1998). As Casas de Apoio atuam no cuidado à saúde de seus moradores, mediante o acompanhamento em consultas, administração dos remédios, fornecimento de alimentação e condições de moradia adequadas (São Paulo, 2002).

A compreensão do contexto de vida do morador, bem como o conhecimento de sua história de vida, suas crenças e representações, são condições necessárias para a organização das ações de saúde a serem oferecidas na assistência a essas pessoas. Segundo Luz (1997), é preciso ir além da atuação sobre a doença, sendo necessário fomentar a convivência saudável entre os indivíduos e a busca por um ambiente agradável para se viver - em uma concepção biopsicossocial da saúde.

Essas entidades lidam com questões que ultrapassam o âmbito do binômio saúde-doença, ao serem coadjuvantes de um processo de reintegração de seus moradores à sociedade, que tende a considerar a diversidade de modos de existir como uma ameaça aos seus anseios de disciplina e ordem (São Paulo, 2002). Dessa forma, as Casas de Apoio articulam uma teia complexa de inter-relações entre os diferentes atores sociais, implicados na prestação do cuidado à saúde, que compõem a organização e administração dos serviços, a população assistida e as entidades sociais envolvidas no processo de intervenção.

Nesses locais, as coordenações são responsáveis por viabilizar as práticas de assistência por meio de funções administrativas (como obtenção de recursos financeiros e materiais em busca da autosuficiência) (Fischer, 1998), entremeadas por relações interpessoais decorrentes da convivência entre moradores e a equipe de trabalho da instituição.

A assistência prestada ao portador do vírus HIV requer a consideração de fatores inerentes às representações sociais dessa doença, para que se possa prestar um atendimento mais efetivo. Com relação à Aids, é possível identificar diferentes manifestações estigmatizantes e desqualificadoras dirigidas ao portador. A informação de soropositividade pode proporcionar ao portador impactos sociais negativos, pois a partir do instante em que se revelou (no sentido de tornar conhecida e de ser desvelada ao outro) essa condição, são acionados os mecanismos que irão lhe conferir sua rotulação (Ferreira \& Figueiredo, 2006).

Visando aprofundar os conceitos de estigma e discriminação em relação à Aids, Parker e Aggleton (2001) entendem que se tratam, sobretudo, de manifestações da desigualdade e exclusão social (ao se criarem hierarquias entre estigmatizados e não estigmatizados-marginalizados), das relações de 
poder (ao sujeitar o indivíduo à aceitação do próprio estigma, por se considerar socialmente desviante) e de seu controle.

Com relação à família, as forças de associação dos membros familiares são postas em ameaça na condição de estigma de um dos seus: a família tanto pode assumir uma postura solidária, quanto ser reticente em relação ao indivíduo marginalizado "em virtude dos sentimentos de desonra que ele acabou despertando" (Paugaman, 1999, p.78), criando-se uma situação que pode sobrepujar a relação de obrigação-retribuição. Enquanto muitas doenças mobilizam a família em torno de seu ente enfermo, a Aids pode conduzir a uma profunda desestabilização e, sobretudo, desagregação familiar (Soares \& Figueiredo, 2001).

A condição daquele que se torna objeto de discriminação e rejeição no seio familiar permeia a história de muitos indivíduos que adquirem o HIV, notadamente os que se tornam moradores das Casas de Apoio. Ao pensar sobre a população residente de uma Casa de Apoio para portadores do HIV, a falta de condições para a permanência em seu próprio lar - quando este até existe - remonta a situações de falta de recursos materiais e também socioafetivos.

No Brasil, a epidemia de Aids assume atualmente um perfil relacionado à pauperização e feminização da população mais atingida. A esse perfil podem-se acrescentar outras tendências encontradas na análise comparativa dos dados epidemiológicos realizada no período compreendido entre 1980-1991 até março de 2002 (Gotlieb, Castilho, Buchalla, 2002), como: 1) desaceleração e interiorização; 2) heterossexualização (a partir de 1993) do contágio, atingindo principalmente as mulheres; 3) feminização e envelhecimento; 4) aumento de sobrevida; e 5) pauperização (Brasil, 2002).

Ribeirão Preto (São Paulo, Brasil), município de médio porte com cerca de meio milhão de habitantes, segundo dados apresentados pela Secretaria de Saúde da Prefeitura Municipal, registrou oficialmente o primeiro caso em 1986. O valor atual do coeficiente de prevalência leva o município a ocupar, no ranqueamento da síndrome, a sexta posição no país e a terceira no Estado de São Paulo. O perfil dos casos notificados de 1986 a 2006 na cidade indica a faixa etária de 30-34 anos como a mais atingida, a categoria de exposição heterossexual seguida pelo uso de drogas, havendo pequena diferença dos números de casos registrados entre homens e mulheres no ano de 2006 (Ribeirão Preto, 2007).

\section{Objetivo}

O estudo objetivou conhecer a organização, funcionamento e prestação da assistência pelas coordenações das três Casas de Apoio a portadores de HIV/Aids em Ribeirão Preto-SP.

\section{Material e métodos}

Participaram do trabalho as coordenadoras das três Casas de Apoio a pacientes portadores de HIV/Aids, situadas na cidade de Ribeirão Preto-SP (Brasil). O critério de inclusão utilizado para recrutar o sujeito do estudo era de a pessoa ocupar a posição de gerente da organização no ano de 2003, quando os dados foram coletados. Considerou-se como coordenador aquele indivíduo designado para "reunir e sincronizar atividades e pessoas de forma que funcionem harmoniosamente na realização dos objetivos da organização" (Dever, 1988, p.49). As participantes formalizaram sua anuência com a pesquisa mediante assinatura do Termo de Consentimento Livre e Esclarecido.

O conceito de administração utilizado na pesquisa foi aquele apresentado também por Dever (1988, p.48) como o "processo que supervisiona a produção dos serviços da saúde".

Desse modo, dentre as atribuições esperadas para serem desenvolvidas pelas casas, figurava a oferta de assistência multidisciplinar no nível da comunidade, administrando junto ao pacientemorador o cronograma da assistência à saúde (consultas e atendimentos nos serviços especializados de saúde), os tratamentos, a alimentação e as orientações e condições de higiene recomendadas na moradia (São Paulo, 2002). 
Além disso, a inclusão social dos pacientes-moradores e sua reinserção familiar, para aqueles que a perderam por algum motivo, fazem parte das funções que compõem a missão das Casas Apoio e foram preconizadas pelo Ministério da Saúde em documento para orientação dessas entidades (Brasil, 1998).

Os elementos relacionados constituem alguns dos parâmetros em que o trabalho será pautado para estudar as práticas administrativas das Casas de Apoio.

Este estudo, de caráter exploratório e descritivo, estruturou-se com base nos seguintes instrumentos para coleta dos dados:

1 questionário constituído por 23 perguntas com base no Guia de Recomendações do Ministério da Saúde do Brasil (1998), que possibilitaram traçar um perfil estrutural das instituições. As questões podem ser classificadas em: estrutura física; estrutura financeira e social; recursos disponíveis e seu manejo; segmento da população que a Casa recebe e sua permanência; quadro de funcionários e normas de biossegurança, tendo sido verificado in loco o cumprimento ou não dos itens questionados.

Esse tipo de questionário permitiu descrever a estrutura e funcionamento da Casa de Apoio e o conhecimento ou não do coordenador sobre alguns tópicos abordados.

2 roteiro de entrevista semi-estruturada sobre as atribuições do coordenador. O roteiro de entrevista semi-estruturada buscou dar maiores condições para abordar, com as coordenações, a construção de processos que subsidiam as práticas de assistência e funcionamento da instituição.

A entrevista, por excelência, é tida como recurso que possui grande utilidade por ser a porta de acesso para uma qualidade diferenciada de dados "que nenhuma outra estratégia prevê, quando se trata de pesquisa com sujeitos humanos" (Biasoli-Alves, 1989, p.2). Possibilita que atitudes, valores, sentimentos e opiniões venham à tona na relação entrevistador-entrevistado, assim como o reflexo de acontecimentos anteriores no discurso presente;

3 observação, em sua modalidade livre, do cotidiano das instituições, ao longo de três visitas, de uma hora cada (em média), realizadas em diferentes períodos do dia;

4 diário de campo, contendo anotações registradas ao longo de todo o processo de coleta dos dados.

Esses dois últimos instrumentos possibilitaram a caracterização do cenário e do local onde se deu a coleta dos dados.

A oportunidade de participar do primeiro fórum de entidades denominado "Coopera Ribeirão", promovido pela Secretaria do Desenvolvimento e Bem-Estar local, contribuiu para conhecer algumas questões que permeiam o trabalho de diferentes organizações não governamentais, e, mais detidamente, daquelas que estão inseridas no atendimento de pessoas portadoras de deficiências (incluindo-se aí as Casas de Apoio para portadores do HIV/Aids). Essa experiência forneceu um preparo importante para o início do trabalho de campo.

O referencial metodológico adotado para a análise foi uma adaptação do método hermenêuticodialético, respaldado nas pesquisas qualitativas em saúde. Segundo essa proposta, a consideração dos contextos de enunciação (que na presente pesquisa foram obtidos por meio das observações e diário de campo) permite uma melhor compreensão da fala dos atores sociais. A complementaridade entre os dados obtidos estabelece como uma das finalidades da análise "ampliar o conhecimento sobre o assunto pesquisado, articulando-os ao contexto cultural do qual faz parte" (Gomes, 1994, p.69).

Por meio dos itens abordados no questionário estruturado foi possível elaborar a descrição de cada local, bem como dimensionar aspectos relativos ao seu funcionamento. Além dessa fonte, as entrevistas, observações e diário de campo foram analisados por meio dos seguintes passos: ordenação com base em uma leitura exaustiva e flutuante; imersão que consistiu na releitura do material obtido de cada local investigado, com foco nas singularidades desses equipamentos e de suas respectivas coordenações; classificação, concomitante ao passo anterior, e análise, com a definição de eixos e subeixos para a articulação com o objetivo do trabalho, preparando para a interpretação e discussão dos dados.

O projeto foi aprovado pelo Comitê de Ética em Pesquisa do Centro de Saúde-Escola da Faculdade de Medicina de Ribeirão Preto. 


\section{Resultados e discussão}

Os resultados aqui apresentados versam sobre a análise dos locais estudados, nos seus aspectos estruturais, de funcionamento e organização. Além disso, apresentam-se algumas colocações das próprias entrevistadas, que contribuem para dimensionar suas práticas administrativas. Também há referência à questão da inclusão social de seus moradores, uma vez que se trata de uma das funções desempenhadas por esses locais de acordo com os documentos oficiais.

Integraram esse estudo as três Casas de Apoio para portadores de HIV/Aids de que se tem registro na cidade de Ribeirão Preto, as quais pertenciam a um conjunto formado por um universo de 66 entidades, dentre estas 44 eram organizações assistenciais com outras atuações sociais (Soares, Santos, Forster, 2003).

Duas delas atendiam à população adulta, homens e mulheres, e a terceira, exclusivamente crianças. Foram instaladas em imóveis amplos, cujas condições estruturais estavam adequadas às atividades a que se propuseram, em consonância com as normas de biossegurança. Uma delas, a qual estava recentemente instalada em um novo imóvel na época da coleta dos dados, aguardava a visita da Vigilância Sanitária para avaliação das instalações. Embora estivessem regulamentadas junto aos órgãos de fiscalização municipal, o regimento interno (documento que orienta as ações da organização) estava em fase de elaboração.

As dificuldades financeiras também foram uma característica compartilhada por essas organizações. Viviam, sobretudo, às custas de doações e possuíam alguns benefícios públicos, pouco representativos frente às despesas que compunham os gastos para manutenção de uma Casa de Apoio para portadores de HIV/Aids. A relação com os serviços públicos foi construída de forma dúbia, pois, no âmbito governamental, o reconhecimento da importância desses serviços não assegurava o aporte de recursos e as condições mínimas necessárias para seu funcionamento (Fischer, 1998).

A necessidade de angariar recursos para o financiamento das organizações era um dos pontos de contato com a sociedade e o poder público. O abrigo infantil parecia despertar uma maior sensibilização social do que aquelas casas que acolhiam adultos, o que resultava em um volume maior de contribuições. As camadas média e popular eram mais receptivas aos pedidos de auxílio, enquanto a classe empresarial parecia valorizar a capacidade produtiva dessas pessoas:

ele investe na criança que ele sabe que vai viver ... é difícil você tentar uma parceria com alguém ou com uma empresa que ele sabe que a criança vai morrer ... é como se o investimento dele fosse para o túmulo de uma certa forma. (informação oral obtida de uma das entrevistadas)

Outro ponto em comum observado foi a presença feminina à frente de suas coordenações todas as três eram administradas por mulheres que se iniciaram nas organizações como voluntárias e, por motivos diferentes, engajaram-se na formação desses equipamentos sociais.

As organizações de apoio incluídas nessa pesquisa possuem, como missão, o restabelecimento de seus moradores e a realização de ações concretas que promovam condições favorecedoras à qualidade de vida. Como norma de funcionamento, as Casas de Apoio estipulam um período máximo para permanência do morador, que, ao longo de sua passagem, espera-se que esteja em condições de ser reinserido em sua família e, portanto, em sua comunidade de origem. No entanto, em muitos casos, a realidade mostrou-se diferente do "discurso oficial". Foram identificados casos de moradores permanentes nessas Casas, ao passo que outros possuíam uma rotina de idas e voltas em que a Casa parecia funcionar como um porto seguro para os momentos de maior dificuldade.

Os moradores dessas Casas de Apoio foram qualificados como aqueles que não possuem estrutura (sic, coordenadora 1) tanto física e social, como familiares para que pudessem lidar com as decorrências do convívio com o HIV/Aids. Eram aqueles cuja família não tinha condições de mantêlos em sua casa, por falta de recursos e/ou meios concretos de sobrevivência. Ou, mais freqüentemente, detentores de uma história de vínculos familiares fragilizados, insuficientes para 
garantir a convivência familiar com o portador e a sua doença. A esse perfil aliam-se duas questões: associação da pauperização da doença a uma dificuldade de manter a capacidade produtiva exigida pelo mercado de trabalho, o que pode refletir na dependência do portador em relação à família; a estigmatização social que atinge a todos que convivem com a doença, direta ou indiretamente (Ferreira \& Figueiredo, 2006).

Nas atividades de rotina desses locais, foi marcante a questão dos cuidados de saúde, uma vez que, praticamente em todos os dias da semana, alguém teria de sair para alguma consulta, realização de exames ou acompanhamento de rotina da saúde. Como ilustração dessa medida, as três Casas possuíam murais onde se encontrava uma agenda de consultas e retornos da semana, que, em uma das casas para adultos, ficava exposta em uma área de convivência comum.

Nessa perspectiva, o cuidado de saúde era prestado por outros serviços e se fazia presente mediante o acompanhamento das consultas e controle dos horários, para permitir a organização das saídas de todos os que necessitassem cumprir com essas atividades. Também se efetivava por meio da administração dos medicamentos e pela viabilização de uma alimentação que pudesse suprir as necessidades dos moradores.

Por outro lado, a promoção de atividades de integração social e/ou familiar era tímida, fazendo-se por meio de saídas, passeios programados e, em alguns casos, participação em cursos externos. Mesmo quando esses eventos aconteciam, poderiam ser considerados pouco eficientes em garantir a plena integração do morador com a sociedade ou sua família. Eram muito raras as visitas recebidas pelos internos, segundo as coordenadoras, mas, por outro lado, foram relatadas situações em que os moradores saíram para visitar seus familiares.

$\mathrm{Na}$ casa-abrigo infantil, a escola foi um local privilegiado onde se dava a relação das crianças com o espaço além dos muros da casa, o que aliviava a rotina de visitas ao Hospital das Clínicas (HCFMRP-USP). Além disso, foram citados passeios a locais públicos de convívio, como sorveterias, shopping center, circo, com o intuito de oferecer diversão, colocando as crianças em contato com alternativas de lazer mais próximas aos anseios infantis. Nos fins de semana, freqüentemente ocorriam festas promovidas por grupos de voluntários, o que deu a impressão, em alguns momentos, de ser um recurso utilizado para afastar a tristeza, estimulando-se a alegria à exaustão.

Esses modos de realizar o contato dos moradores com o espaço social aponta para o que Araújo (2005) constatou em seu estudo sobre a administração de uma casa de apoio infantil. Trata-se da dificuldade de encontrar o ponto de equilíbrio entre a instituição querer tornar-se a mediadora exclusiva do morador com o espaço externo e ter uma postura consciente das limitações de seu papel, enquanto organização.

No Quadro 1 são apresentados alguns dados referentes às organizações focalizadas pelo presente estudo.

Ao todo somaram-se 68 vagas, estando 44 ocupadas quando foi feito o levantamento. Uma casa estava com ocupação de $50 \%$ das vagas disponíveis, enquanto as outras duas estavam acima de sua meia capacidade. Juntas contabilizaram um total de 33 funcionários e 24 voluntários. Uma casa era mantida por uma entidade de cunho religioso, com a maioria dos funcionários na categoria de voluntário e participando da organização há pouco mais de um ano. Duas casas (uma para crianças e outra para adultos) eram mantidas por uma entidade assistencial, optando pelo vínculo empregatício (contratação) em detrimento do voluntariado, em menor número de funcionários. Nessas organizações, observou-se uma tendência comum ao Terceiro Setor: o avanço crescente da busca de profissionalização mediante a admissão de pessoas com capacitações específicas e a contratação remunerada (Fischer, 1999). As fontes de recursos eram: a comunidade, as pessoas físicas e jurídicas, e uma fundação institucional. 
Quadro 1. Apresentação das Casas de Apoio para portadores de HIV/aids de Ribeirão Preto-SP (2003).

\begin{tabular}{|l|c|c|c|}
\hline & CASA 1 & CASA 2 & CASA 3 \\
\hline Tempo de existência & 9 anos & 9 anos & Alugado \\
\hline Natureza do imóvel & Doação & Doação & 17 \\
\hline Total de vagas & 11 & 40 & 8 \\
\hline Total de residentes & 8 & 28 & Em adaptação \\
\hline Condições de biossegurança & Adequadas & Adequadas & 7 \\
\hline Funcionários(as) & 8 & 18 & 2 \\
\hline Voluntários(as) & 14 & Acima de 8 (variável) & $\begin{array}{c}\text { Fundação de Apoio ao } \\
\text { Ensino, Pesquisa e }\end{array}$ \\
\hline $\begin{array}{l}\text { Fonte de recursos } \\
\text { financeiros (mais } \\
\text { representativa) }\end{array}$ & $\begin{array}{l}\text { Doações da comunidade } \\
\text { pertencente a uma igreja }\end{array}$ & $\begin{array}{c}\text { Doações de pessoas físicas } \\
\text { e jurídicas }\end{array}$ & $\begin{array}{c}\text { Assistência do HC-FMRP- } \\
\text { USP (FAEPA-FMRP-USP) }\end{array}$ \\
\hline
\end{tabular}

\section{A coordenação na voz de suas protagonistas}

As coordenadoras tinham entre trinta e 49 anos de idade, com vínculo institucional de oito anos ou mais. Eram funcionárias contratadas para jornadas de oito horas diárias, profissionais de áreas administrativas distintas da saúde, e apresentavam identificação com os ideais e objetivos da organização.

As três coordenadoras haviam sido voluntárias junto às entidades antes de assumirem a coordenação e serem contratadas, função que exigia dedicação integral às atividades. Relatavam que o aprendizado da função ocorreu, acima de tudo, pela (con)vivência: “...faço assim, né, cursos relacionados tipo para Aids... uma preparação... Mas assim, a minha maior experiência é a minha experiência de vida... a prática, né... a convivência no dia-a-dia no trabalho..." (informação oral obtida de uma das entrevistadas).

A postura administrativa adotada no exercício da função de zelar pelo bem-estar no convívio entre os moradores permitiu a emergência da dimensão subjetiva em meio ao contexto técnico da gerência e do cuidado (Sá, 2001). Em alguns momentos, esteve implícito um conflito entre o trabalho técnico-administrativo e o "cuidado subjetivo", considerando a importância das atribuições administrativas na distribuição do tempo dedicado à instituição:

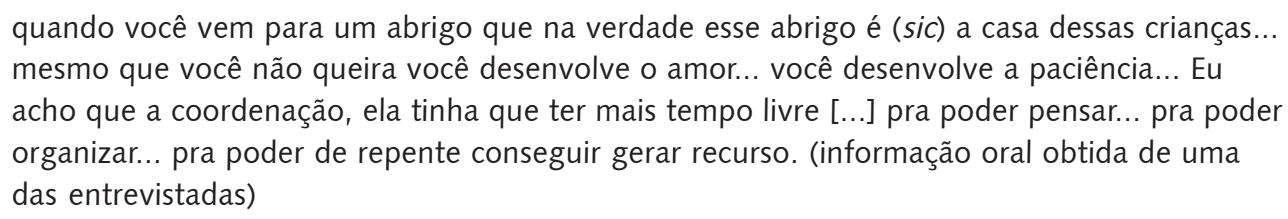

As coordenadoras valorizaram, particularmente, aspectos do contato e do convívio cotidiano como recurso para a reabilitação dos moradores. Assim, a presença feminina não se limitava à função de coordenação e apontava claramente para a condição do papel da mulher como cuidadora (Romanelli, 1999; Sarti, 1996; Costa, 1983).

As atribuições cotidianas foram definidas como multifuncionais: captação de recursos, o agendamento das consultas, a escuta acolhedora de moradores e funcionários, a limpeza da casa - se assim fosse necessário: 
[...] é, a gente é bem ambivalente mesmo, né... por causa das dificuldades financeiras... da falta de recursos... a gente faz várias coisas [...] eu faço mais a questão da PRÁTICA da casa né... da rotina da necessidade. Quebra-galho [...] eu acho que função específica... dizer pra você que se tem, que se pode dentro de um abrigo, onde você está lidando com seres humanos [...] você fazer uma rotina de trabalho é: nós vimos que isso cai por terra [...] é sem rotina como uma rotina, a rotina é não ter rotina. (informação oral obtida de uma das entrevistadas)

\section{A expectativa da inclusão}

Tendo em vista que também se espera das Casas de Apoio a integração social de seus moradores, adquiriu importância elucidar as interfaces praticadas com a sociedade. Permeada pela exclusão do convívio social, a sociedade é, ao mesmo tempo, geradora de espaços comunitários como as Casas, que acolhem os frutos dessa condição de marginalização e segregação. Abadia-Barrero (2002) refere que, ao observar os caminhos desenhados pela epidemia e pela própria qualidade de vida das pessoas portadoras, a assistência deveria ser integrada à comunidade, e não em locais específicos e isolados.

A relação com o ambiente externo foi mediada pelo estabelecimento de regras, que limitavam a circulação dos moradores e restringiam sua autonomia. O contato externo era percebido pelas coordenações como possibilidade de retorno a modos de vida indesejáveis relacionados às vicissitudes do ambiente da rua (Costa, 1983): "eu acho que a pessoa se recuperar de saúde pra voltar pra rua, pra voltar pra droga, pra voltar pra prostituição, nosso trabalho é como se tivesse ficado meio frustrado, né?" (informação oral obtida de uma das entrevistadas).

As coordenadoras das casas para adultos mantiveram um discurso semelhante em relação à dificuldade de integração de seus moradores, ora por receio de que pudessem acabar retomando hábitos de vida que trariam prejuízos à saúde, se lhes fosse dada a oportunidade de livre circulação no mundo externo à casa, ora pela própria dificuldade de aceitação, por parte da sociedade, da condição de vida dessas pessoas. Muitas vezes, o morador que tivesse maior liberdade de ir e vir (sair para a rua) era visto como alguém que havia conquistado um voto de confiança da coordenação.

A instituição, por sua vez, cumpria o papel de realizar uma transformação existencial na vida dessas pessoas, ao passo que a família e a sociedade figuravam como os locais de origem do abandono e do desamparo (Guirado, 1986). A organização tentava reconstruir o espaço privado na vida dessas pessoas e, conseqüentemente, restaurar os sentidos de afiliação, uma vez que os laços sociais haviam se esgarçado devido à discriminação social produzida pela doença. Percebeu-se que as coordenações tinham uma expectativa de contribuir para a implementação de mudanças de hábitos de vida dos moradores e entendiam que, para que essas transformações fossem eficazes e duradouras, era necessário manter uma vigilância contínua e constante destinada a coibir seus desvios.

A inclusão social mostrou-se um ponto crítico nas ações realizadas por essas Casas que, embora buscassem proteger seus moradores, acabavam por promover mecanismos de reinserção pouco efetivos, redimensionando e legitimando alguns processos de exclusão que atingem o doente de Aids de camadas populares. Ainda que pese a estigmatização a que está submetido o 
paciente que convive com HIV/Aids, o contato externo era visto pelas coordenações como ameaçador em relação aos progressos alcançados no recinto das Casas de Apoio.

Por outro lado, trata-se de uma questão anterior à chegada do portador à casa, na medida em que remete a um contexto social excludente associado a histórias de vida marcadas por distanciamento familiar e vulnerabilidade social (Parker \& Camargo Júnior, 2000).

\section{Conclusões e considerações finais}

A caracterização das Casas de Apoio do município de Ribeirão Preto condiz com a apresentada por Gonçalves (2006) em um estudo focalizando as casas existentes no estado de São Paulo, em relação à sua estrutura organizacional, captação de recursos e sua mão-de-obra formada majoritariamente por voluntários.

As organizações caracterizaram-se por uma relação diferenciada com sua clientela, pautando-se por princípios como: a reabilitação da saúde dos moradores, fortalecimento e reparação de suas condições como indivíduo (dignidade humana, auto-estima) e cidadão detentor de direitos (assistência integral e humanizada). A necessidade de encontrar soluções para questões emergenciais e dificuldades rotineiras de manutenção das Casas de Apoio mostrou a existência de um mecanismo organizacional ágil e eficiente para o funcionamento organizacional.

O contato próximo com a rotina dos moradores, fator apontado pelas coordenadoras como importante para o exercício do cuidar, favoreceu a formação de um clima de aproximação com o usuário. Com isso, foram fortalecidos os laços afetivos com a Casa; ao passo que a busca de contato com o que existe para além dos muros desses equipamentos foi sutilmente desestimulada pelas coordenações, limitando o resgate da autonomia.

Foi observado que, embora se mantenha em uma posição distanciada, a família ocupa um lugar de importância no processo saúde-doença das pessoas que convivem com o HIV/Aids e requer um preparo para a convivência com o ente enfermo. O contato com a família guarda, em si, um sentido de reparação do pertencimento a um lugar social. Seria importante que, tanto entre as crianças portadoras como entre os portadores adultos, a retomada desse contato fosse envolvida por uma estratégia de instrumentalização do núcleo familiar frente à doença, e de potencialização de recursos de enfrentamento coletivo, incorporando um olhar sensível a outras dificuldades freqüentemente associadas à condição de pauperização.

As Casas de Apoio operacionalizaram uma resposta social às conseqüências trazidas pela epidemia de Aids no seu aspecto humanitário e caritativo. Esses locais mostraram-se um importante recurso para o suporte biopsicossocial ao paciente de Aids, como um complemento ao tratamento, sobretudo daqueles indivíduos desprovidos de suporte e apoio familiar.

Considera-se que seria importante rever um dos objetivos dessas instituições, que pauta sua estruturação e organização, no que tange a serem locais de permanência provisória e de restabelecimento de saúde - e também da condição psicossocial de seus moradores. Esse repensar implicaria olhar as necessidades e o funcionamento das entidades sob outra perspectiva, operando mudanças sobre a administração dos recursos disponíveis para atender a essas propostas. Dessa forma, assumir que, muitas vezes, essas casas tornam-se os lares definitivos de seus moradores, o que exigiria repensar sua organização e a convivência dentro de tal realidade. Isso implica dar maiores condições de autonomia para enfrentar a vida em sociedade e suas adversidades - tão presentes para o cidadão portador do vírus HIV, auxiliando-o na reestruturação não apenas do seu cotidiano, como dos seus objetivos de vida.

O conhecimento das concepções de gerenciamento que orientam as potencialidades e limites de serviços prestadores de assistência organizados pela sociedade civil lança luz sobre os papéis que esses equipamentos vêm desempenhando como promotores do exercício da cidadania. 


\section{Limitações do estudo}

Por envolver um universo específico e reduzido das organizações civis existentes no município, o trabalho, por vezes, incorre no risco de mitigar determinados aspectos da realidade muito próprios do contexto da Aids como fenômeno social. Outro ponto para ser revisto seria a não inclusão, no estudo, de outros informantes-chave das Casas, que poderiam ampliar a visão sobre seu funcionamento administrativo.

\section{Colaboradores}

Os autores Marisley Vilas Bôas Soares, Aldaísa Cassanho Forster e Manoel Antonio dos Santos participaram, igualmente, de todas as etapas de elaboração do artigo.

\section{Referências}

ABADIA-BARRERO, C.E. Crianças vivendo com HIV e Casas de Apoio em São Paulo: cultura, experiências e contexto domiciliar. Interface - Comunic., Saúde, Educ., v.6, n.11, p.55-70, 2002.

ARAUJO, J. Associação François-Xavier Bagnoud do Brasil: apenas mais um caminho. In: CRUZ, E. F.; ABADIA-BARRERO, C.E. (Orgs.). Criança, adolescente e Aids: abra este diálogo. São Paulo: Fórum das ONG's-AIDS do Estado de São Paulo, 2005. p.88-94.

BIASOLI-ALVES, Z.M.M. Entrevistas: formatos e análises. Ribeirão Preto, 1989. (Mimeogr.).

BRASIL. Ministério da Saúde. Secretaria de Políticas de Saúde. Coordenação Nacional de DST e Aids. Bol. Epidemiol. AIDS, v.15, n.1, p.5-9, 2002.

Ministério da Saúde. Coordenação Nacional de DST e Aids. Guia de recomendações: casa de apoio em HIV/Aids. Brasília, 1998.

COSTA, J.F. Ordem médica e norma familiar. 2.ed. Rio de Janeiro: Graal, 1983.

DEVER, G.E.A. A epidemiologia na administração de serviços de saúde. In: A epidemiologia na administração de serviços de saúde. São Paulo: Pioneira, 1988. p.4770.

FERREIRA, R.C.M.; FIGUEIREDO, M.A.C. A reinserção no mercado de trabalho: barreiras e silêncio no enfrentamento da exclusão por pessoas com HIV/Aids. Medicina (Ribeirão Preto), v.39, n.4, p.591-600, 2006.

FISCHER, R.M.; FALCONER, A.P. Desafios da parceria governo e terceiro setor. Rev. Adm., v.33, p.12-9, 1998.

FISCHER, R.M. Trabalho e terceiro setor. Inform. Fipe, v.1, p.20-2, 1999.

GALVÃO, J. 1980-2001: uma cronologia da epidemia de HIV/Aids no Brasil e no mundo. Rio de Janeiro: ABIA, 2002. 
GOMES, R. A análise de dados em pesquisa qualitativa. In: MINAYO, M.C.S. (Org.). Pesquisa social: teoria, método e criatividade. 3.ed. Petrópolis: Vozes, 1994. p.67-80.

GONÇALVES, C.F. As casas de apoio no contexto das políticas públicas de saúde para as DST/HIV/Aids no Estado de São Paulo, no período de 1996 a 2003. 2006. Dissertação (Mestrado) - Medicina Preventiva, Faculdade de Medicina, Universidade de São Paulo, São Paulo. 2003.

GOTLIEB, S.L.; CASTILHO, E.A.; BUCHALLA, C.M. O impacto da Aids na esperança de vida, Brasil, 2000. Brasília, v.16, n.1, p.17-23, 2002.

GUIRADO, M. Instituição e relações afetivas: o vínculo com o abandono. São Paulo: Summus, 1986.

LUZ, M.T. Cultura contemporânea e medicinas alternativas: novos paradigmas em saúde no fim do século XX. Physis - Rev. Saúde Coletiva, v.7, p.13-43, 1997.-

MENEGHEL, S.N. et al. Mulheres cuidando de mulheres: um estudo sobre a Casa de Apoio Viva Maria, Porto Alegre, Rio Grande do Sul, Brasil. Cad. Saúde Pública, v.16, n.3, p.747-57, 2000.

PARKER, R.; AGGLETON, P. Estigma, discriminação e Aids. Rio de Janeiro: ABIA, 2001.

PARKER, R.; CAMARGO JR., K.R. Pobreza e HIV/Aids: aspectos antropológicos e sociológicos. Cad. Saúde Pública, v.16, supl.1, p.89-102, 2000.

PAUGMAN, S. O enfraquecimento e a ruptura dos vínculos sociais: uma dimensão essencial do processo de desqualificação social. In: SAWAYA, B. (Org.). As artimanhas da exclusão: análise psicossocial e ética da desigualdade social. Petrópolis: Vozes, 1999. p.67-86.

RAMOS, S. O papel das ONGs na construção de políticas de saúde: a Aids, a saúde da mulher e a saúde mental. Ciênc. Saúde Colet., v.9, n.4, p.1067-78, 2004.

RIBEIRÃO PRETO. Programa Municipal de DST/Aids. Indicadores epidemiológicos 2007. Disponível em: <http://www.ribeiraopreto.sp.gov.br/index.html>. Acesso em: 10 jun. 2007.

ROMANELLI, G. O processo saúde/doença em famílias de baixa renda e a ação do Estado. In: ENCONTRO ANUAL DA ANPOCS, 23., 1999, Caxambu. Anais... Caxambu, 1999. p.1-19.

SÁ, M.C. Subjetividade e projetos coletivos: mal-estar e governabilidade nas organizações de saúde. Ciênc. Saúde Colet., v.6, n.1, p.151-64, 2001.

SÃO PAULO. Secretaria de Saúde do Estado de São Paulo. Centro de Vigilância Sanitária. Portaria Conjunta 2 CVS/CRT-DST/Aids. São Paulo, 2001. Disponível em: <http:// www.cvs.saude.sp.gov.br>. Acesso em: 4 jul. 2002.

SARTI, C.A. A família como espelho: um estudo sobre a moral dos pobres. Campinas: Autores Associados, 1996.

SOARES, M.V.B.; FIGUEIREDO, M.A.C. Representações sobre Aids e o atendimento domiciliar: um estudo diferencial entre pacientes e cuidadores. Investigação Rev. Cient. Univ. de Franca, v.3, n.4, p.7-13, 2001.

SOARES, M.V.B.; SANTOS, M.A.; FORSTER, A.C. Os significados do voluntariado para coordenadores de Casas de Apoio para portadores de HIV/Aids. In: LEAL-SILVA, L.L. et al. (Orgs.). Arquitetura de uma ocupação: orientação profissional: teoria e técnica. São Paulo: Vetor, 2003. p.187-200. v.1. 
SOARES, M.V.B.; FORSTER, A.C.; SANTOS, M.A. Caracterización de las Casas de Apoyo a portadores de HIV/Sida en Ribeirão Preto (São Paulo, Brasil) y sus prácticas de administración. Interface - Comunic., Saúde, Educ., v.12, n.24, p.169-80, jan./mar. 2008.

La finalidad del estudio fue conocer la organización, funcionamiento y prestación de cuidado por las coordinaciones de las tres Casas de Apoyo a portadores de HIV/Sida en Ribeirão Preto-São Paulo. Se realizaron entrevistas semi-estructuradas con las coordinadoras respecto a sus funciones, se aplicó un cuestionario sobre los aspectos estructurales del local y se registraron observaciones del cotidiano de las instituciones (diario de campo). Se obtuvo que, legalmente, eran organizaciones regidas por entidades del tipo asistencialista-humanitario e intentaban adecuarse a las normas técnicas y exigencias para su funcionamiento. Recibían subvención del ayuntamiento local, pero eran sostenidas principalmente por donativos de la sociedad civil. Las coordinaciones eran desempeñadas por mujeres, predominantes en los equipos de funcionarios y voluntarios. En sus discursos, se observó una postura administrativa multifuncional y dificultad en realizar la inclusión social de los habitantes, debido al preconcepto o reglas de funcionamiento de las casas. Se concluye que,

administrativamente, las casas cumplían con aquello que se proponían, pero necesitarían atentar para que, como agentes sociales, fomentaran la inclusión social.

Palabras clave: Casas de convalecencia. HIV. Síndrome de Inmunodeficiencia adquirida. Cuidado. Inclusión social. 